\title{
Parameters Evolution of Orthorhombic Martensite Lattice in VT16 Titanium Alloy During Heating
}

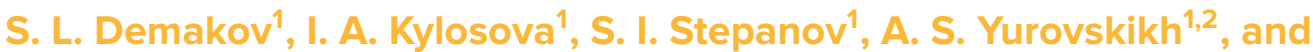 \\ N. V. Kuznetsov ${ }^{1}$ \\ ${ }^{1}$ Ural Federal University, 19, Mira str., Ekaterinburg, Russian Federation \\ ${ }^{2}$ M.N. Miheev Institute of Metal Physics of Ural Branch of Russian Academy of Sciences, $18 \mathrm{~S}$. \\ Kovalevskaya Street, Yekaterinburg, Russia, 620137
}

\section{Abstract}

The material of the study was $(\alpha+\beta)$-titanium alloy VT16. Samples were quenched from different temperatures and then they were heated in situ on X-ray diffractometer. It has been established that the period " $b$ " of the orthorhombic martensite lattice showed negative values of the coefficient of thermal expansion during heating.

Corresponding Author:

I. A. Kylosova

aiana.semkina@urfu.ru

Received: 25 February 2019

Accepted: 9 April 2019

Published: 15 April 2019

Publishing services provided by

Knowledge E

(c) S. L. Demakov et al. This article is distributed under the terms of the Creative Commons

Attribution License, which

permits unrestricted use and

redistribution provided that the

original author and source are

credited.

Selection and Peer-review unde the responsibility of The Ural school-seminar of metal scientists-young researchers Conference Committee.
Keywords: titanium alloys, XRD-analysis, orthorhombic martensite, coefficient of thermal expansion.

\section{Materials and Methods}

The material of the study were samples of VT16 titanium alloy (Ti-3Al-5V-4.5Mo, weight. \%), water quenched from 780,800 and $820^{\circ} \mathrm{C}$ (time of exposure was 30 minutes). Water quenched specimens were placed into XRD-diffractometer, equipped electric furnace with a vertical $\theta-\theta$-goniometer in the angular range of $2 \theta=52 \ldots 66^{\circ}$ in $\mathrm{K} \alpha \mathrm{Cu}$ radiation $(\lambda=0.154178 \mathrm{~nm})$ in the temperature range $40 \ldots 280{ }^{\circ} \mathrm{C}$ (temperature step of $\left.20^{\circ}\right)$, for estimation of orthorhombic martensite lattice dependence on temperature.

\section{Results and Discussion}

Martensitic needles are present in the microstructure of VT16 alloy specimens quenched from various temperatures. The phase composition of the samples was determined using X-ray phase analysis. The diffractogram patterns are shown in Fig. 1. The position of the $\alpha$-phase line varies little in the temperature range of quenching from 780 to 820 ${ }^{\circ} \mathrm{C}$. The observed $\beta$-phase is residual - not transformed during quenching. The lines position of $\alpha$ "- martensite varies in different directions. Line (200), related to the period 
"a", moves toward large angles with an increase in the hardening temperature. Lines (130) and (022) are shifted towards smaller angles. Since $\alpha$ "-martensite lattice behaves anisotropically. The data on the phase composition and the period of $\alpha$ "-martensite of quenched samples are summarized in Table 1.

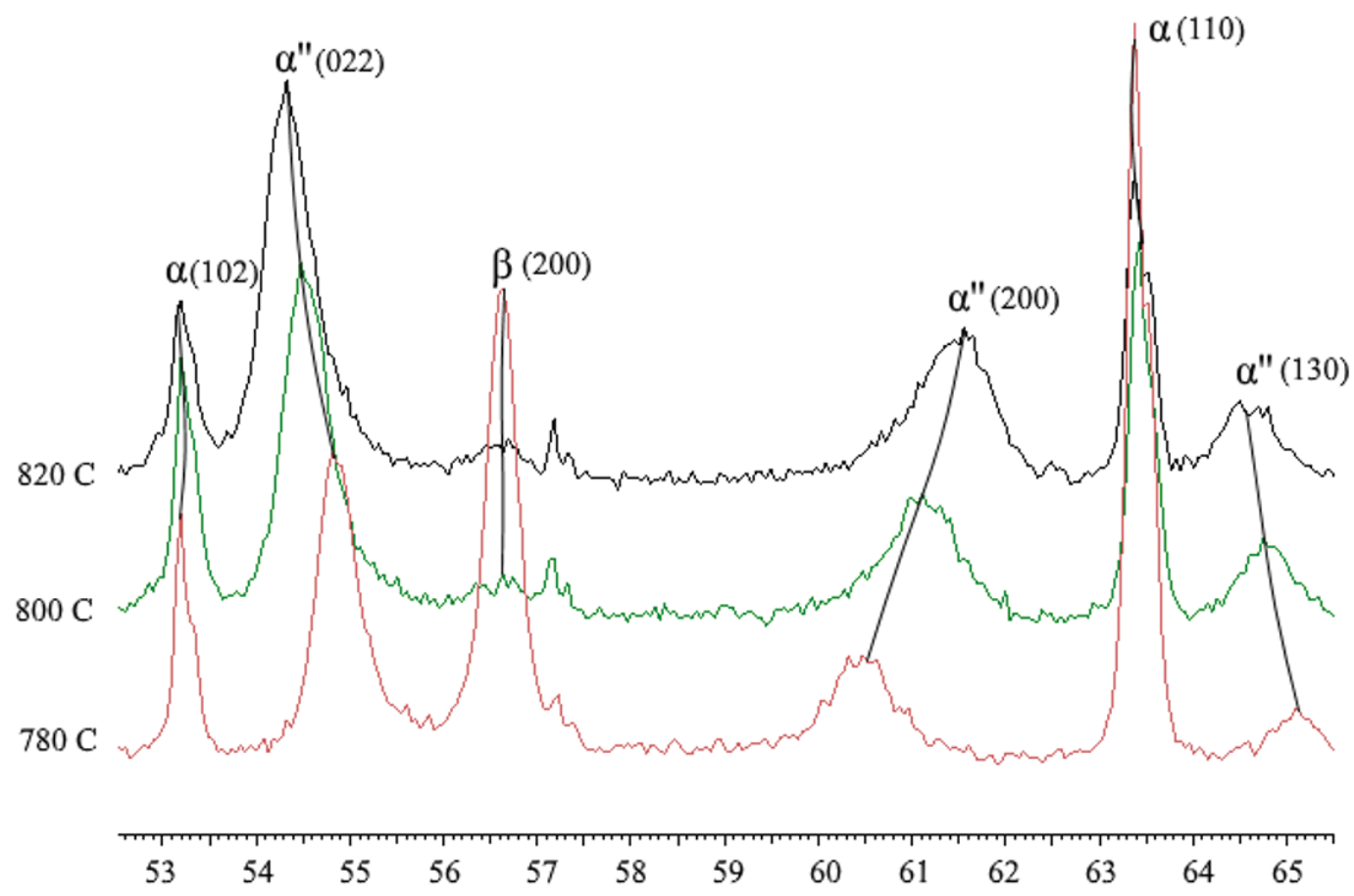

Figure 1: The VT16 diffractogram patterns of quenched from different temperatures samples.

TABLE 1: Phase composition, rhombicity $(\sqrt{ } 3 a / b)$ and $\alpha$ "-orthorhombic martensite lattice parameters of quenched VT16 alloy.

Quenching
temperature,
${ }^{\circ} \mathrm{C}$
780
800
820

\begin{tabular}{c|c|c|c|c|}
$\begin{array}{c}\text { Phase } \\
\text { composition }\end{array}$ & $\begin{array}{l}\text { Orthorhombic martensite } \\
\text { parameters, } \mathrm{nm}\end{array}$ & lattice & $\mathrm{R}(\sqrt{ } \mathrm{3a} / \mathrm{b})$ \\
& $\mathrm{a}$ & $\mathrm{b}$ & $\mathrm{c}$ & \\
\hline$\alpha " \beta+\alpha$ & 0,3062 & 0,4862 & 0,4617 & 1.09 \\
\hline$\alpha "+\beta+\alpha$ & 0,3031 & 0,4905 & 0,4630 & 1.07 \\
\hline$\alpha "+\beta+\alpha$ & 0,3016 & 0,4927 & 0,4641 & 1.06 \\
\hline
\end{tabular}

Samples quenched from different temperatures were studied in situ in an X-ray diffractometer. The position of the lines shows a strong temperature dependency, and not only the direct dependency, when the lines are shifted towards smaller angles, but also the reverse, when the lines are shifted towards larger angles $2 \theta$. A change in the intensity of the lines clearly demonstrates the occurrence of the inverse $\alpha$ " $\beta$ transformation. In this case, the intensity of the martensite lines decreases, and the intensity of the $\beta$ phase lines increases sharply. In the samples quenched from the maximum temperature, reverse martensitic transformation was not observed; the intensity of $\alpha$ "- martensite and 
$\beta$-phase lines remains unchanged over the entire temperature range. At $\mathrm{Tq}=800^{\circ} \mathrm{C}$ the beginning of the reverse transformation is observed at $\mathrm{T}=140{ }^{\circ} \mathrm{C}$. At $\mathrm{T}=200{ }^{\circ} \mathrm{C}$, the reverse transformation is basically completed and martensite remains only in small quantities, the intensity of its lines changes slightly with further heating. At quenching temperature of $780^{\circ} \mathrm{C}$, the high-temperature $\beta$-phase is mainly fixed with a small amount of martensite, which is completely transformed into the $\beta$-phase already at $\mathrm{T}=100{ }^{\circ} \mathrm{C}$. We associate the presence of the temperature range of the reverse transformation primarily with the inhomogeneity of the high-temperature $\beta$-phase [1]. The temperature dependence of the relative change in the lattice periods of the orthorhombic martensite during heating and the diffraction patterns of alloy samples quenched from various temperatures are shown in Fig. 2 . The values of the lattice parameters before heating were used as the initial ones.

Figure 2 The diffractogram patterns of VT16 titanium alloy samples quenched from T = $820^{\circ} \mathrm{C}(\mathrm{c})$ and the temperature dependence of the relative change in the lattice periods of the orthorhombic martensite during heating

The coefficient of thermal expansion along the axes of the $\alpha$ "-martensite orthorhombic lattice in the temperature range $30 . . .100^{\circ} \mathrm{C}$ of the quenched VT16 alloy is presented in Table 2. Analysis of the obtained data showed that the parameter "a" increases, while the parameter "b" decreases in the process of heating, changing the values of the parameter "c" can be associated with the course of the transformation.

TABLE 2: CTE along the axis of $\alpha$ "-orthorhombic martensite lattice in the temperature range from 40 to $100^{\circ} \mathrm{C}$ of VT16 quenched alloy.

\begin{tabular}{|c|c|c|c|}
\hline $\mathrm{T}_{q},{ }^{\circ} \mathrm{C}$ & \multicolumn{3}{|c|}{$\mathrm{CTE} \cdot 10^{-6}, \mathrm{~K}^{-1}$} \\
\hline & Along a & Along b & Along C \\
\hline 780 & 81 & -37 & -8 \\
\hline 800 & 53 & -27 & 7 \\
\hline 820 & 45 & -14 & -1 \\
\hline
\end{tabular}

Summarizing, a dependence of the rhombicity $\mathrm{R}(\sqrt{ } 3 \mathrm{a} / \mathrm{b})$ degree on temperature was constructed. The rhombicity dependence on temperature is shown in Fig. 3. The dependence of the change in the slope angle on the degree of rhombicity is well traced. Namely, the slope angle is maximum when martensite has the highest rhombicity degree (at low quenching temperatures) and vice versa for higher quenching temperatures (for martensite with the lowest rhombicity degree), the slope angle is low. The reverse martensitic transformation occurs when martensite has a certain "critical" rhombicity $[2,3]$. According to literature data for the alloy Ti-3Al-7Mo [4], the "critical" degree of rhombicity is the value $\mathrm{R}=1.11$. In the case studied, the "critical" $\mathrm{R}$ has a value close to 

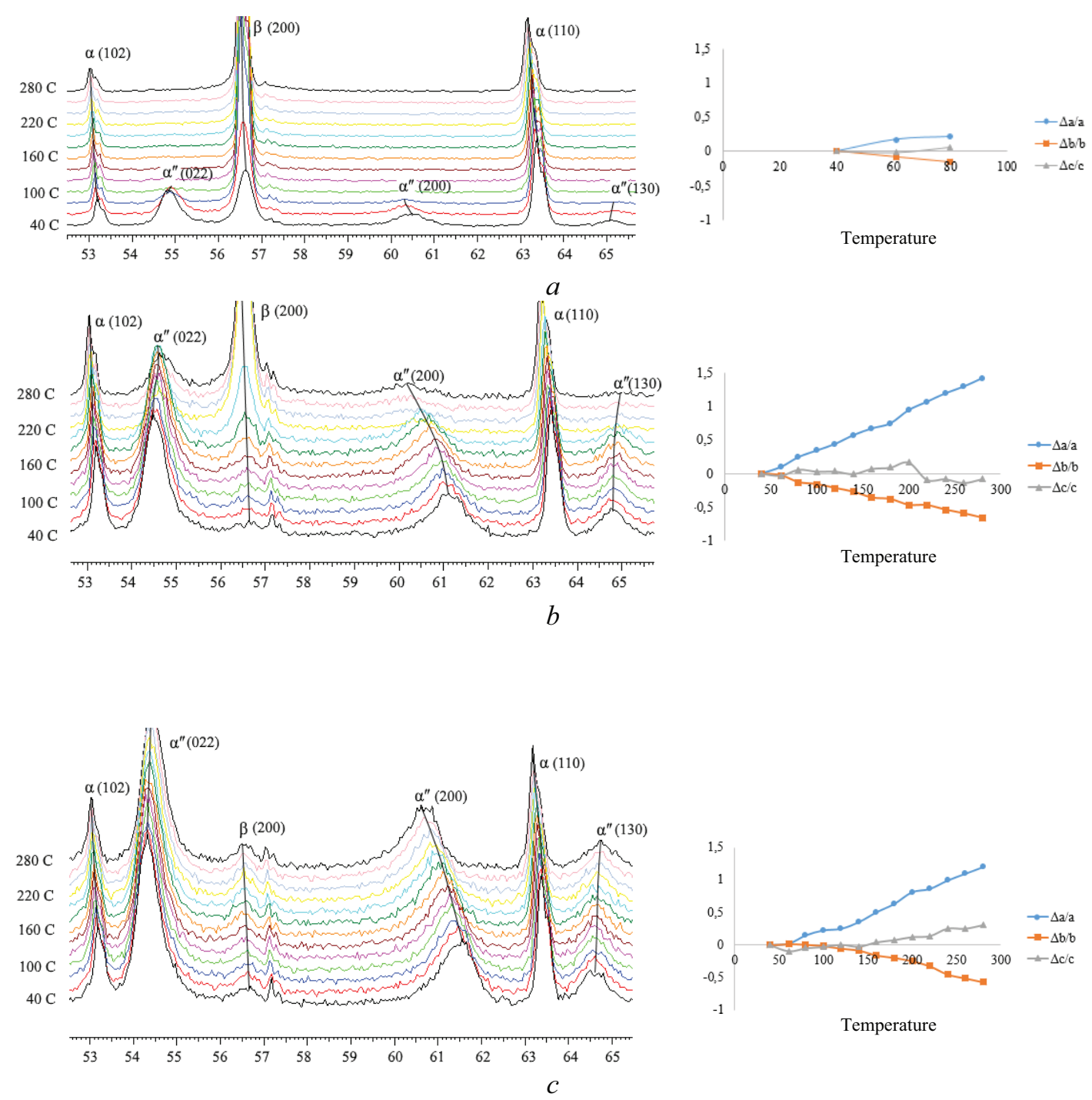

Figure 2: The diffractogram patterns of VT16 titanium alloy samples quenched from temperatures $780{ }^{\circ} \mathrm{C}$ (a) and $800{ }^{\circ} \mathrm{C}(b)$ and the temperature dependence of the relative change in the lattice periods of the orthorhombic martensite during heating.

1.08. This difference is explained by a change in alloying, when part of molybdenum is replaced by vanadium, namely, the presence of vanadium reduces the indicators of the "critical" degree of rhombicity.

\section{Conclusion}

The anisotropy characteristics of the thermal expansion of the orthorhombic martensite lattice of the VT16 titanium alloy, quenched from different temperatures in the $(\alpha+\beta)$ region, were determined. The most significant anisotropy was found in the samples quenched from a temperature close to the critical one. 


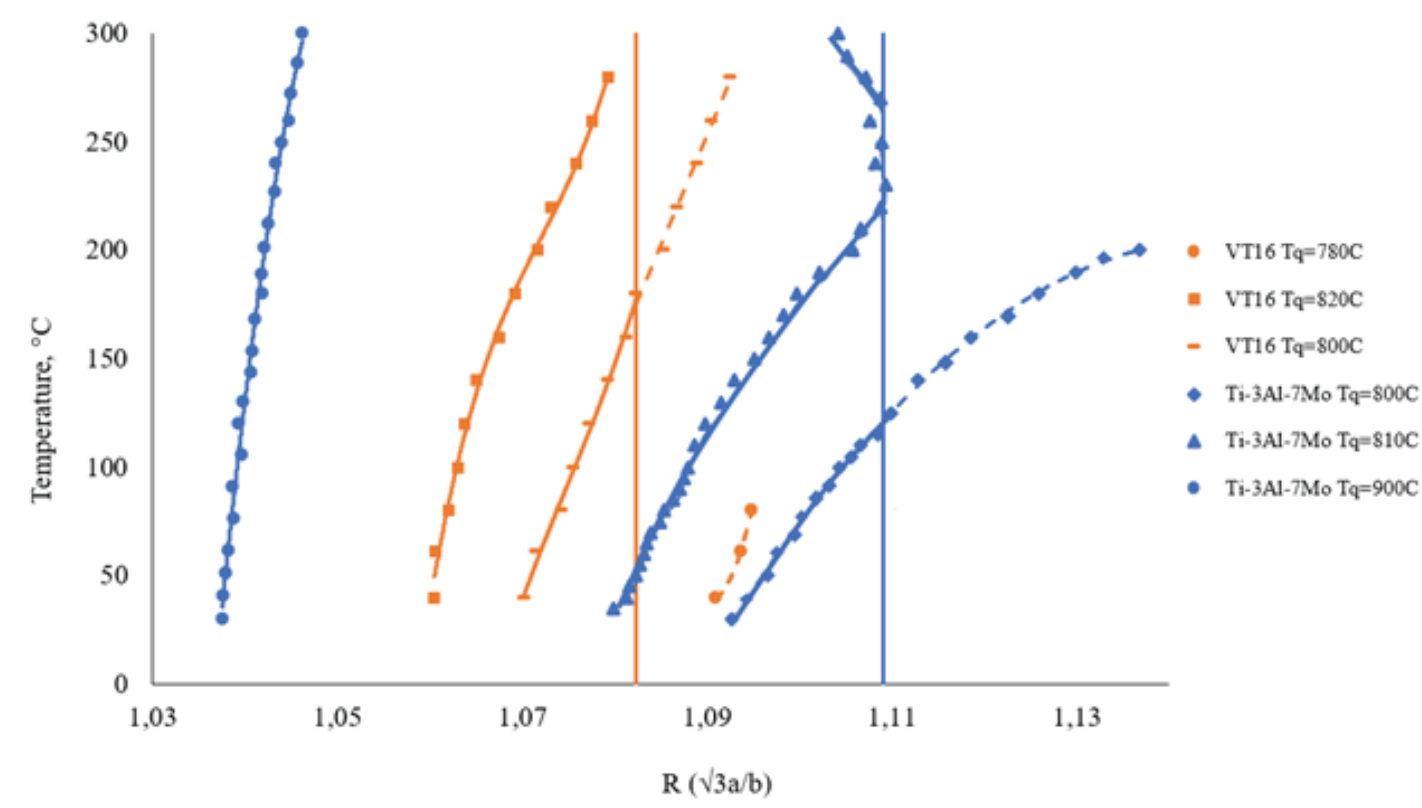

Figure 3: Dependence of the degree of rhombicity on the change in the orthorhombic martensite lattice parameters of VT16 and Ti-3Al-7Mo [4] samples during heating.

As a result of the work, the coefficients of thermal expansion of the orthorhombic martensite lattice of titanium alloy VT16 samples were determined.

The degree of rhombicity, above which the reverse martensitic transformation begins, is determined. It is established that the presence of vanadium leads to a decrease in the rhombicity values of the martensite lattice, above which the reverse martensitic transformation occurs.

The study was supported by the grant of the Russian Science Foundation N $N^{\circ} 18-13-$ 00220

\section{References}

[1] V. Gridnev, O. Ivasishin, C. Oshkaderov. Physical fundamentals of high-speed thermal treatment of titanium alloys. Naukova Dumka, Kyiv, 1986, 253 p.

[2] D.L. Moffat, U.R. Kattner, Stable and metastable Ti-Nb phase diagrams Metall. Trans. A.1988 19 2389-2397.

[3] D.L. Moffat, D.C. Larbalestier, The competition between Martensite and Omega in quenched Ti-Nb alloys Metall. Trans. A. 198819 1677-1686. 
[4] S. Demakov, I. Semkina, A. Yurovskikh, Parameters Evolution of Orthorhombic Martensite Lattice Ti-Mo-Al Alloys Studied by in Situ T-XRD IOP Conf. Ser.: Mater. Sci. Eng. 2018301012003 